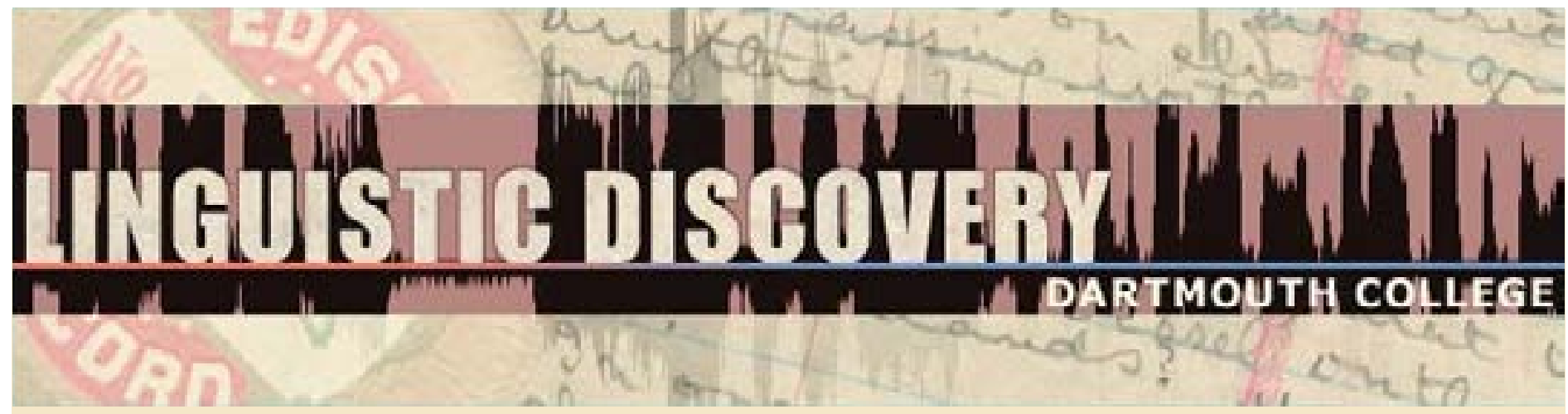

Volume 8 Issue 1 2010
Semantic Maps and Word Formation: Agents, Instruments, and Related Semantic Roles

Eugenio R. Luján

Universidad Complutense de Madrid

doi: 10.1349/PS1.1537-0852.A.349

url: http://journals.dartmouth.edu/cgi-bin/WebObjects/ Journals.woa/1/xmlpage/1/article/349
Linguistic Discovery

Published by the Dartmouth College Library Copyright to this article is held by the authors. ISSN 1537-0852 linguistic-discovery.dartmouth.edu 


\title{
Semantic Maps and Word Formation: Agents, Instruments, and Related Semantic Roles
}

\author{
Eugenio R. Luján
}

Universidad Complutense de Madrid

The semantic map methodology has been applied mainly to the analysis of the multifunctionality of grammatical morphemes-they allow one to deal with this problem without having to decide between monosemic and polysemic analyses. Similar issues arise when dealing with derivational morphemes and word formation patterns so that this methodology can be extended to their analysis. As a case study, causal semantic roles are surveyed in this paper, both synchronically and diachronically. Only Agents and Instruments seem to have specific word formation patterns, while Force and Means cannot be identified as proper semantic roles in word formation.

Semantic maps based on word formation patterns also allow for interesting comparisons to those drawn on the basis of grammatical morphemes. Given that they are based on different data, but semantically overlap to a certain extent, this can help to throw some light on the general validity of the results of the methodology. For instance, from a diachronic perspective there is an interesting difference concerning the evolution of Agent and Instruments markers as grammatical morphemes from word formation patterns-in word formation it is Agents that evolve into Instruments and this is the evolution expected according to the predictions made on the basis of general abstraction scales.

\section{Introduction ${ }^{1}$}

\subsection{Semantic maps}

In the last years, a new methodology has gradually developed for the semantic analysis of grammatical morphemes - semantic maps. ${ }^{2}$ Haspelmath (2003:213) defines them in this way:

A semantic map is a geometrical representation of functions in "conceptual/semantic space" that are linked by connecting lines and thus constitute a network.

Semantic maps allow one to deal with the problem of the multifunctionality of grammatical morphemes without having to decide between monosemic and polysemic analyses (Haspelmath 2003:211-213). ${ }^{3}$ The methodology of semantic maps has been applied mainly to the analysis of grammatical morphemes (affixes and adpositions) as exemplified by Haspelmath (1999) for "Dative" and for various other categories in Haspelmath (2003:220-230): indefinite pronouns, reflexives, and Instrumental and related semantic roles.

Similar problems concerning multifunctionality arise when, instead of analyzing grammatical morphemes, we turn our attention to derivational morphemes and word formation patterns in

\footnotetext{
${ }^{1}$ For the development of the ideas expressed in this paper, I have greatly benefited from discussions on this topic with Julia Mendoza, César Hernández, Ricardo Dorado, and César Ruiz. I am very grateful to Martin Haspelmath and an anonymous reviewer for their comments and suggestions on an earlier version of this paper. This paper is part of the research project FFI2009-13292-C03-02, financed by the Spanish Ministry of Science and Innovation.

${ }^{2}$ For problems of terminology see Haspelmath (2003:219-220), who discusses other alternatives. See Croft (2003:133-139) for the distinction between semantic maps proper, which are language specific, and the "conceptual space" or underlying universal semantic structure.

${ }^{3}$ Lexical items seem to behave in the same way (see Haspelmath 2003:237-238 and Geeraerts 1997).
}

Linguistic Discovery 8.1:162-175 
general. We can start by considering some examples of the multifunctionality of derivational morphemes in various languages. ${ }^{4}$

English suffix -er

(1) a. writer

b. lighter

Spanish suffix -dor

(2) a. matador 'bull-fighter', lit. 'killer'

b. destornillador 'screwdriver'

c. comedor 'dining room'
(Agent)

(Instrument)

Latin suffix -culum

(3)
a. poculum 'cup'
(Instrument)
b. cubiculum 'bedroom'
(Locative)

Previous work on semantic maps has shown how the polysemy of grammatical morphemes is not random, but structured according to underlying principles. We can assume that something similar happens with derivational morphemes and word formation patterns, so that the semantic map methodology can be further applied to the analysis of word formation. It is my goal in this paper to discuss how this can be done. I shall deal with some general issues, but the focus will be on Agents, Instruments, and related semantic roles as a case study.

\subsection{Word formation}

Although the semantic map methodology has not been applied to the analysis of word formation patterns, there is no reason to suppose that derivational morphemes behave differently from grammatical morphemes. In fact, taking into account the findings of the intensive work done in the field of grammaticalization in the last thirty years or so, we know now that lexical and grammatical morphemes constitute a continuum, and their meanings are organized in the same way -inside a cognitive frame, we can assume that in both cases there are core and peripheral meanings, but that the borders between these meanings are synchronically blurry, which allows for transitions and semantic changes over time. ${ }^{5}$

Derivational morphemes are in a certain sense midway between lexical and grammatical morphemes. In contrast to the lexicon, the number of derivational morphemes and word formation patterns in any given language is limited. In contrast to grammatical morphemes, the application of such patterns to a given word is not mandatory-leaving aside exceptions such as defective paradigms, if a language has nominal inflection, it must be possible to produce a whole paradigm for a noun, but if a language has augmentative or diminutive suffixes, they may or may not be used with a given word, and it is frequently not easy to predict when this is the case.

\footnotetext{
${ }^{4}$ Only cases in which the word derived by means of the suffix is a noun are taken into account in the examples. I will thus leave aside, for example, the fact that -er is used for the formation of comparatives in English.

${ }^{5}$ See the general framework and the case studies in Geeraerts (1997).
} 
The difference between derivation and inflection is indeed not a radical one, and, as we have just stated, it lies precisely in the compulsory character of grammatical morphemes as opposed to derivational morphemes. Moreover, the same semantic content can be expressed by means of grammatical morphemes or affixes in different languages. For instance, iterative and causative verbal morphemes can be inflectional in some languages, while they are clearly derivational in others. ${ }^{6}$ Grammatical morphemes usually arise from content words following a well known chain of grammaticalization that can be represented as follows:

WORD > CLITIC > AFFIX > ANALYZABLE PART OF A MORPHEME

It is from this perspective that it is interesting to explore whether the semantic map methodology can be applied to the analysis of the meanings or functions of word formation patterns as well. Note that the expression "word formation patterns" will be used in this context instead of saying merely "affixes" because it may also be applied to composition, as in nouns like English screwdriver (Instrument) or Spanish guardabosques 'ranger' (Agent), from guardar 'watch over' and bosque 'forest'.

\section{Agents, Instruments, and Related Semantic Roles in Word Formation}

\subsection{Causal semantic roles}

Various causal roles have been identified in syntactic studies-Agents, Instruments, Causes, Intermediaries, Forces, and so on. Agents are prototypically animates, especially humans, and are characterized by control and intentionality over the action that they perform. Some inanimate entities can also have control over the action, but obviously they cannot have any intentionality. This has led to the identification of the semantic role Force, typically played by entities such as natural forces and emotions.

As opposed to Agents, Instruments are prototypically inanimates and can be controlled. This second trait seems to be more salient in Instruments than the lack of animacy, given that inanimate entities that cannot be subject to control rarely show up as Instruments. Intermediaries are somehow midway between Agents and Instruments-they are prototypically animates, especially humans, but are controlled by an Agent. We find, thus, a scale that goes from viewing them as mere Instruments up to conceiving them as co-participants in the action performed, that is, "split agency" (Luraghi 2003:34).

\subsection{Causal semantic roles in word formation}

We cannot know for sure how many and which semantic roles are grammaticalized in the languages of the world, given that this type of semantic approach has not been previously applied in a systematic way to word formation patterns. Focusing on causal semantic roles as a case study, only Agents and Instruments usually have specific word formation patterns. ${ }^{7}$ Using the same criteria as for grammatical morphemes (Haspelmath 2003:217), this allows one to

\footnotetext{
${ }^{6}$ For instance, Hebrew verbal inflection includes specific intensive and iterative forms, the so called pi‘ēl conjugation, while iterative suffixes in Latin such as -tāre in verbs like captāre (from capere 'take') are clearly derivational - the iterative form may or may not exist in Latin, while in principle it is expected for every verb in Biblical Hebrew.

${ }^{7}$ Word formation patterns for causes are grammaticalized in some languages, as is the case in Sundanese, which has a reason nominalizer (Comrie and Thompson 1985:356-357).
} 
recognize them as separate semantic roles in word formation. Evidence is not difficult to find in languages of various families, e.g.:

a) In Vedic the suffix $-\operatorname{tar}^{8}$ is used to derive Agent nouns from verbal roots; relying on Tichy's (1995) data, it seems that no Instrument noun is formed by means of this suffix. In fact, it is interesting to remark that this suffix is only used with verbal roots that involve intentionality on the part of the subject of the action, that is, with Agents proper, while roots in which the subject is more properly an Experiencer (sleep, hunger, be thirsty, and so on) or having meanings such as 'shine' or 'glitter' are in principle excluded from this possibility (Tichy 1995:32-33).

b) The Basque suffix -le/-tzaile, when added to verbal roots, provides Agent nouns, such as ekarle 'carrier' from ekarr(i) 'bring' or antolatzaile 'organizer' from antola(tu) 'organize', while Instruments are formed by means of -gailu/-ailu/-kailu, as in sendagailu 'remedy' from senda(tu) 'heal' or zerrailu 'lock' from zerra(tu) 'close' (Hualde and Ortiz de Urbina 2003:341-342).

c) The Old Irish suffix -aige is employed to form Agents such as gataige 'thief' (from gat 'theft') or scélaige 'narrator' (from scél 'tidings'). This suffix seems to be the outcome of *-sag-yo-s, that is, a derivative in -yo- from the same root as Old Irish saig- 'seek' (De Bernardo 1999:345-346), providing, thus, a nice instance of the grammaticalization process mentioned in Section 1.2.

Nevertheless, the Agent-Instrument polysemy in word formation patterns is well-known and is extensively documented. I will just provide a few examples in addition to those mentioned in Section 1.1:

a) In French there is a productive suffix -eur used to form Agent nouns. According to the analysis of Fradin (2005), verbs that lack a causal structure are excluded from this formation, thus neither *comporteur (from comporter 'comprise') nor *ressembleur (from ressembler 'resemble') are possible. When the suffix -eur is applied to verbs of perception or psychological events, as in penseur 'thinker' (from penser 'think') it imposes a reading as a causal verb. The suffix is also used to produce Instrument nouns, such as broyeur 'grinder' (from broyer 'grind') or lanceur 'launcher' (from lancer 'launch'). Following Fradin (2005:167-171), the impossibility of derivatives like *monteur (from monter 'go up' or 'bring [something] up') has to do with the fact that the verbs of inherently directed motion have a Figure as subject, thus lacking a causal structure.

b) In Old Irish, Agents are usually formed with the suffix -(a)id/-(a)ith added to a verbal noun, as shown by cétlaid 'singer' (from cétal 'singing'), scríbndid 'writer' (from scribend 'writing'), etc. It is also occasionally employed to denote Instruments, as in deregtith 'razor' (cp. do-érig 'bare, strip') or scrissid 'scraper' (from scris 'scraping').

\footnotetext{
${ }^{8}$ There are, in fact, two different possibilities with this suffix depending on whether the accent falls on the suffix itself or on the verbal root. These two kinds of formations behave syntactically in a different way, too, and have different semantic nuances, but this has no direct bearing on the analysis that we are proposing now. For a comprehensive analysis of these formations see Tichy (1995).
} 
c) In Biblical Hebrew the so-called qāṭil forms are basically active participles and, when used as nouns, Agents like šofet 'judge' or kohen 'priest', but among them we find Instruments like soherah 'buckler' as well.

d) In Russian the suffix - ̌̌čik is almost exclusively found with animate Agent nouns (e.g. otarščik 'shepherd', podsobščik 'helper, assistant'), but it is also found in some inanimate nouns which can be best conceptualized as Instruments, like pikirobščik 'dive-bomber' or tralı̌ščik 'fishing trawler' (Andrews 1996:54-58, 118 fn. 13, and 194-200).

Interestingly enough, word formation patterns for Instrument nouns can show an additional polysemy outside the field of causal semantic roles - the same patterns are frequently employed with Locative nouns. This can be exemplified with cases like the following:

a) The Latin suffix -tōrium (Leumann 1977:300-301) is primarily used to derive Locative nouns from verbal roots, as in dormitōrium 'bedroom' (from dormire 'sleep') or auditōrium 'auditorium' (from audire 'listen'), but it also shows up in Instrument nouns like pōtōrium 'drinking cup' (from pōtāre 'drink').

b) The Sanskrit neuter suffix -tra- (Wackernagel \& Debrunner 1957:701-704) is found in Instrument nouns like śastra- 'knife, sword' (from śas- 'cut down') or vartra- 'dike' (from $v r$ - 'cover') and also in Locative nouns like janitra- 'birthplace' (from jan- 'beget') or kṣetra- 'land, soil' (from kṣi- 'dwell, abide').

c) The Albanian suffix -esë (Newman, Hubbard \& Prifti 1982:166) is found, for example, in the Instrument noun kullesë 'strainer' (from kulloj 'I strain') and in the Locative kthesë 'turn, curve, bend' (from kthej 'I turn').

d) In Turkish the suffixes -(I) $t$ and -(A) $k$ both appear in Instruments and Locatives (Kornfilt 1997:448-449), e.g. taşıt 'vehicle' (from taş 'carry') vs. geçit 'passage, ford' (from geç 'pass') and tarak 'comb' (from tara 'comb') vs. batak 'marsh, swamp' (from bat 'sink').

There are also a number of cases in which we find the same suffix used for the three roles. We have already mentioned in (2) the Spanish suffix -dor, which can be found in Agent, Instrument, and Locative nouns. In Old English the suffix $-\operatorname{er}(e)$ is almost exclusively used for Agents (e.g. writere 'writer'), but the Instrument pūnere 'pestle' (from pūnian 'pound') and the Locative scēawere 'watch-tower' (from scēawian 'look at') are also attested.' The Hungarian deverbal suffix -o/-ö derives Agents (e.g. iró 'writer'), Instruments (hegyezö 'pencil sharpener'), and Locatives (társalgó 'parlor') as well (Comrie and Thompson 1985:355).

As for other less prototypical causal semantic roles, such as Force and Means, it seems that they cannot be identified as separate roles proper in the sense that no word formation pattern is exclusive to them. However, from a semantic point of view some nouns formed by means of Agent suffixes are better anaysed as Forces and some nouns formed by means of Instrument suffixes should rather be considered as Means. Reference grammars do not usually provide semantic analyses of word formation patterns in enough detail, so it is difficult to gather appropriate extensive information on this point. However, if we focus on Old Greek and Latin as case studies, we can make the following observations.

\footnotetext{
${ }^{9}$ An extensive analysis of the -er(e) formations in Old English can be found in Kastovsky (1971).
} 
- In Old Greek ${ }^{10}$ the suffix -térion is used to form Instrument nouns, such as potêrion 'cup' (from the same root as pínō 'drink'), sēmantếrion 'seal' (from sēmaínō 'make a signal') etc., and also to derive Locative nouns, such as bouleutếrion 'council-chamber' (from bouleúō 'deliberate'), dikastérion 'court of justice' (from dikázō 'judge'), etc. (Chantraine 1933:62-64). As with other suffixes serving to form both Instruments and Locatives, there are some formations that can be interpreted both ways, such as kratêrion 'crater, mixing vessel'(from keránnumi 'mix'), which can be understood both as the Instrument with which to mix (wine and water) or the place where they are mixed. A very interesting specific use of this suffix is to form names of religious rites and sacrifices. These can be best conceptualized as fulfilling the semantic role Means- the anabatérion or 'sacrifice for fair voyage' (from anabainō 'go on board') is thus not the Instrument with which one gets on board, but the means to assure that one is going to do it.

- Something similar happens in Old Greek with the suffix -tro-. It is typically used for the formation of Instruments (Chantraine 1933:331-333), such as zôstron 'belt' (cp. zốnnūmi 'gird'), élutron 'bow-case' (cp. eilúo 'enfold, enwrap'), etc., but it is also found for the formation of a small number of Agents (e.g. daitrós 'one that carves and portions out', cp. daíomai 'divide'), and it is a productive suffix to form nouns designing wages or rewards, as well. These can be best understood not as Instruments proper but as Means, such as kómistron 'reward for a messenger' (cp. komizō 'carry'). It is also found serving to form Locative nouns in cases such as léktron 'bed' (cp. lékhomai 'lie down') or théātron 'theatre' (cp. theáomai 'gaze at').

- In this language we also find the suffix -mōn, typically used to derive Agents from verbal roots, such as hēgemốn 'leader' (cp. hēgéomai 'lead'). It is also used for forming Instrument nouns in technical language, such as stếmōn 'warp'. Quite interestingly, the same suffix is also found in kheimốn 'wintry, stormy weather'. It shows the traits [+control/-intentionality] and taking into account the uses of this word in Homer, it can be best analysed as a Force. ${ }^{11}$

- In Latin the suffix -culum (Olsen 1988:29) is found in Instruments such as gubernāculum 'helm' (from gubernāre 'be at the helm, steer') or uehiculum 'vehicle' (from uehere 'drive, ride'). This suffix is productively used in the formation of Locative nouns such as hibernācula 'winter quarters' (from hibernāre 'spend the winter') or umbrāculum 'shade' (from umbrāre 'cast a shadow on'). However, some of the nouns formed with this suffix are better analysed as Means, as is the case with piāculum 'expiatory offering or rite' (from piāre 'expiate')

\footnotetext{
${ }^{10}$ The data on Old Greek are taken primarily from Chantraine (1933), although they have been checked with standard reference grammars of this language.

${ }^{11}$ In fact, Chantraine (1933:170-174) defined -mōn as an "animate" suffix in contrast to the "inanimate" suffix -ma. This opposition is still observable to a certain extent in the uses of kheimón vs. kheîma in Homer. Kheimốn is found in certain passages, like Odyssey 4.566, in coordination with other prototypical forces.
} 
The conclusions reached so far can be summarized in the following semantic map (Figure 4). ${ }^{12}$

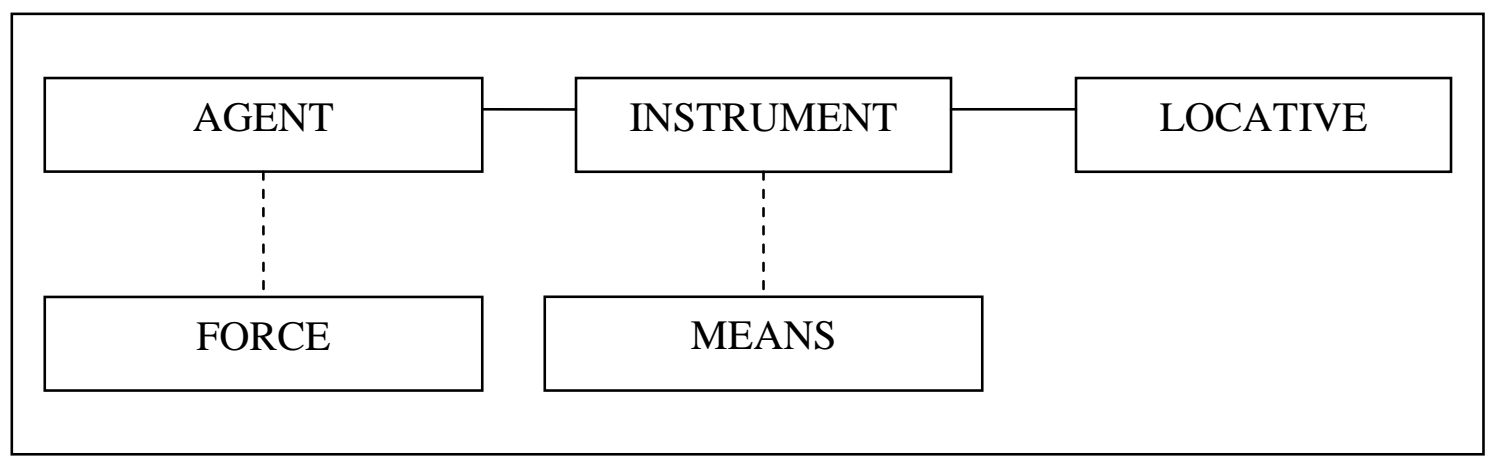

Figure 4: Semantic map of Agent, Instruments, and related semantic roles in word formation

\subsection{Semantic change in word formation patterns}

In the same way as linguistic universals, ${ }^{13}$ semantic maps can be dynamicized to provide diachronic predictions of change. ${ }^{14}$ In a given semantic map, the extension and/or change of meaning of a given grammatical morpheme is expected to follow the lines of the map without jumps to unconnected functions (Croft et al. 1987, Haspelmath 2003:233-237). For instance, if the map above (Figure 4) is right, it is not expected that a suffix used for the formation of Agent nouns comes to be used for the formation of Locative nouns unless it is also used for the formation of Instruments.

However, a synchronic map does not tell in which direction the evolution is bound to occur, in this case whether it is Agents that will evolve into Instruments or the other way around. As in the case of semantic maps of grammatical morphemes, the analysis of the extant evidence in various languages can serve to establish what the usual path of change is and may allow us to draw the arrows that show the expected evolution.

In fact, there have been previous attempts to determine the usual path of semantic evolution in this field. Dressler (1986:526), working inside the framework of Natural Morphology, assumed that the polysemous concept of Agent manifests the following hierarchical structure:

\section{AGENT > INSTRUMENT > LOCATIVE OR SOURCE/ORIGIN}

This structure would thus reflect its organization according to the animacy hierarchy and the diachronic evolution of the meaning of the Agent word formation patterns would follow this direction. However, Dressler's proposal of a unidirectional change has been challenged in various papers, especially Rosemberg (2007), on the basis of the analysis of French derivatives

\footnotetext{
${ }^{12}$ As Haspelmath (2003:217-218 and 232) points out, any new language that is looked into can falsify a semantic map, but the methodology of semantic maps at least allows for generating interesting hypotheses that can trigger more research and can be easily tested on additional languages.

${ }^{13}$ Haspelmath $(2003: 232-233)$ remarks that semantic maps embody a series of implicational universals which emerge as a side effect of the creation of a map. As a matter of fact, semantic maps show some interesting similarities to linguistic hierarchies. Both kinds of structures are based on implicational universals, but implicational hierarchies (such as the animacy hierarchy or the hierarchy of grammatical relations) do not rely on multifunctionality, while semantics maps do. Semantic maps, however, have less predictive force than hierarchiesin a hierarchy a prediction concerns all its members above or below a certain one, while the bundle of semantic functions that a given morpheme can have must follow the lines of the semantic map, but limits cannot be predicted so neatly. Hierarchies thus allow for a lesser number of types of languages than semantic maps.

${ }^{14}$ For a recent overview of the dynamicization of synchronic universals see Croft (2003:232-244).
} 
in -eur and similar formations in other Romance languages - she provides interesting evidence that the Agent reading of particular lexical items does not necessarily precede its use as an Instrument.

In this regard, however, it is important to make a difference between the semantic evolution of a given word and the change of meaning of the word formation patterns themselves (Rainer 2005:22-23). And it is the meaning of the patterns that we are concerned with here. Thus, for instance, comparative evidence suggests that the Indo-European suffix *-tēr was originally used for Agent nouns, which is the situation in Vedic and Hittite (Panagl 1977). It is thus no wonder that in the earlier phases of Old Greek (Homer) it is still found in Agents derived from verbal roots, such as dotêr 'giver' (cp. dídōmi 'give'), drēstếr 'laborer' (cp. drô 'do, accomplish'), etc. However, in the Ionian-Attic dialect -tēr was almost completely given up in favor of -tēs in that function, while it was still productive for the formation of Instrument nouns in technical language, e.g. phusētér 'blow-pipe' (cp. phusô 'blow'), helkustér 'crochet, forceps' (cp. helkō 'draw, drag'), etc. (Chantraine 1933:320-329).

A similar evolution is also attested in the Irish suffix -(a)id/-(a)ith analysed above (Section 2.2), and this seems to have been the case with the Latin suffix -tor and the Proto-Germanic suffix *-ärjaz as well-they lacked Instrumental values, while in Romance and Germanic languages they have acquired them (Rainer 2005:33).

In the same fashion, we find that in modern standard Arabic the so-called qatțāl forms, especially in the femenine qațālat, are a productive pattern for the formation of Instruments (Ambros 1969, Kouwenberg 1997:35-36). They have replaced in this function the older miqtāl pattern, found, for example, in Biblical Hebrew mistor 'covert' or mikmoret 'fishing-net'. In the older phases of Semitic languages, this qațāl pattern provided Agent nouns and nouns of occupations, as shown by Hebrew gannāb 'thief' or dayyān 'judge'.

The evolution from Instrument to Locative can also be seen in some of the suffixes that we have already mentioned such as English -er(e) or Sanskrit -tra. However, the possibility that Locative patterns acquire Instrumental meaning must also be taken into account, as proven by Latin -tōrium. A similar case is found in Modern Hebrew with the suffix -iya, which is primarily used to produce Locative nouns (e.g. ma'adaniya 'delicatessen shop', from ma'adan 'delicacy'), but it is also found in containers like mixtaviya 'letter-case' (from mixtav 'letter'), which may have an Instrument reading (Bolozky 1999:125-140).

Thus, according to the evidence that I have been able to gather up to now, the attested semantic evolutions would be as shown in Figure 5.

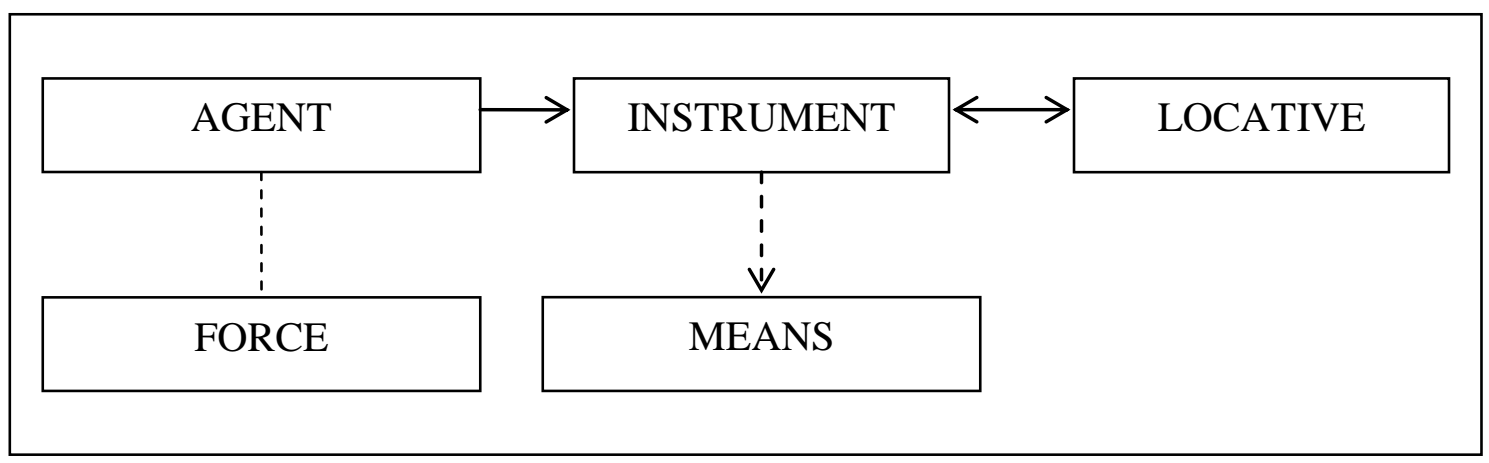

Figure 5: Diachronic semantic map of Agents, Instruments, and related semantic roles in word formation patterns

To understand these processes of diachronic change, it is interesting to focus on the morphological equivalent of the so called "bridging contexts" in syntax, as defined by Evans \& Wilkins (2000). Bridging contexts are those contexts in which a transfer of meaning can take 
place to the form because both possible interpretations are functionally equivalent, even if they differ in what the lexicon and pragmatics contribute in each case. The contextual meaning can thus be lexicalized and will not need the support of a specific context any more to be actualized.

This may be the case, for instance, with some suffixes serving to form Instruments that extend to the formation of Locative nouns or vice versa. There are some border cases, such as English hanger or Spanish llavero 'key holder' (from llave 'key') — is a hanger the object used to hang something (Instrument) or on which to hang something (Locative)? In the Spanish examples, given that in llavero the verb is not specified, as opposed to English key holder, it can be understood either as the object to hold the keys together or the object where you put the keys. In fact, it is interesting to note that we have a continuum of entities referred to by means of nouns formed with the suffix -ero/-era in Spanish, some clearly conceptualized as Locatives, others basically thought of as Instruments and various transitional stages in between (see Figure 6). ${ }^{15}$

LOCATIVE

basurero

(basura 'trash')

'rubbish dump'

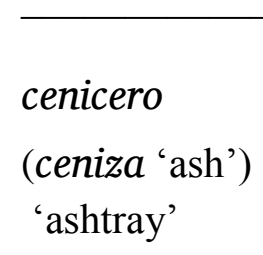

Figure 6: Transition from Locatives to Instruments with the

llavero

(llave 'key')

'key holder'
INSTRUMENT

yogurtera

(yogurt 'yogurt')

'yogurt maker'

Nevertheless, from a cognitive perspective, semantic extension takes place basically through the mechanisms of metaphor and metonymy, so that the extension from Agent to Instrument can be better understood as a particular case of the conceptual metaphor by which human characteristics are transferred to an inanimate object (personification). For instance, CD player, when compared to bullfighter and similar Agent nouns, can be conceptualized as an object that plays CDs when it is an object by means of which someone may play CDs, given that the object itself does not have control or intentionality over the action. The evolution from Agent to Instrument in word formation patterns would be a case of the metaphor that Luraghi (2003:36) specifically calls the "agent metaphor", by which intentionality and control stop being the salient traits and it is only the final outcome of the causal chain that is highlighted so that both Agents and Instruments can be conceived of as effectors. In the case of the evolution from Locative to Instrument or vice versa, we have an interesting instance of the container metaphor.

\subsection{Comparing causal roles in grammatical morphemes and word formation patterns}

I will address in this section the question of how semantic maps drawn on the basis of word formation patterns and on the basis of grammatical morphemes relate to each other. In most cases I can only offer some directions for future research, given that, as already stated, word formation patterns have not been researched systematically from this perspective up to now.

The first issue is trying to understand why word formation patterns for certain semantic roles frequently exist in languages, while for others they do not. Certainly, word formation patterns for

\footnotetext{
${ }^{15}$ For a recent overview of the values of the suffix -ero/-era in Spanish see Amador Rodríguez and Pérez Vigaray (2005). The analysis proposed in this paper fits with what Haspelmath (2003:216-217) labels the monosemist position. According to those scholars, this suffix has only a general relational meaning that they define as the function of objectivization of the entity named by the derivative on the basis of its relation to the base of derivation. It is precisely this kind of general vague meaning that the semantic map methodology can serve to overcome. The ambiguity of the analysis of containers as either Instruments or Locatives has been known for a long time; see Rainer (2005) for a recent overview.
} 
Agent, Instrument, and Locative nouns or Manner adverbials are quite frequent, while word formation patterns specific for Recipients or Conditions are indeed much rarer, if they exist at all. Now, if we compare grammatical morphemes in a given language to word formation patterns, we will immediately see that the number of grammatical morphemes exceeds the number of word formation patterns, that is, the number of grammatical morphemes is higher than the number of derivational morphemes and word formation patterns, so it is no wonder that the number of semantic functions expressed by means of word formation patterns is smaller. Now this leads to further questions - are the semantic functions in one language the same in both cases? Or rather, are the semantic functions "grammaticalized" in word formation in a particular language a subset of those found in grammatical morphemes or else they can have a structure of their own?

This question is very interesting from the point of view of the semantic map methodology and can be reformulated in this way: is the same semantic map valid both for grammatical morphemes and word formation patterns? The comparison can be made at two levels-languagespecific and universal. For instance, we can compare the semantic map of the causal functions of grammatical morphemes (Figure 7) to the semantic map of the causal functions of derivational morphemes in Old Greek, which, in fact, is identical to that proposed as a generalization in Figure 4.

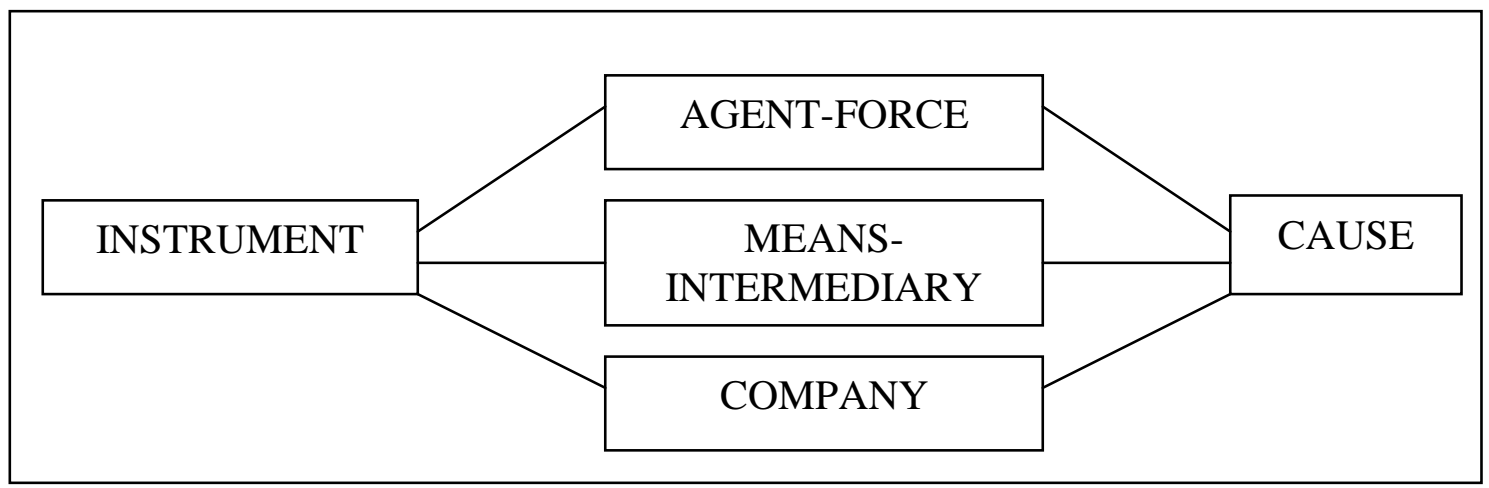

Figure 7: Semantic map of causal functions of grammatical morphemes in Old Greek (based on Crespo 1997)

If we compare these two semantic maps, we first note that, as expected, there are a number of causal semantic functions that can be identified syntactically but are not expressed by means of derivational morphemes or other word formation patterns. However, those that are, appear to be organized in a similar way. In fact, leaving aside the Locative and focusing on causal semantic roles proper, it should be noticed that the semantic map for word formation patterns is just a part of the semantic map of grammatical morphemes. In both cases Instrument seems to be the central item around which the other semantic roles are organized. ${ }^{16}$

More interestingly, this kind of comparison can be made between general semantic maps drawn cross-linguistically for grammatical morphemes and for word formation patterns. Semantic maps are based on implicational universals, so if we take into account what happens with other cross-linguistic patterns based on implicational universals, such as grammatical hierarchies, it is expected that they cross the boundaries of the various linguistic subsystems. However, more research on other semantic functions is needed before it becomes possible to confirm or falsify this claim. If the same semantic maps appear to be valid both for grammatical

\footnotetext{
${ }^{16}$ Although further research is needed, this seems to support Beard's (1990) Parallel Polysemy Corollarygrammatical functions marked by a single category in inflection will be marked by the same affix in derivation more frequently than would be expected by chance.
} 
morphemes and for word formation patterns, this would be important evidence to be taken into account concerning the possibility that there are certain underlying mental structures that would have a reflection both at the syntactic and at the morphological level. ${ }^{17}$

Finally, an interesting point of comparison between both types of semantic maps is diachrony - do diachronic changes move in the same direction along the lines of semantic maps of grammatical morphemes and word formation patterns? We have some hints that this is not necessarily so and more research is also required in this case before we can provide a definitive answer to this question. For instance, Luraghi (2003:32) has drawn attention to the fact that the evolution INSTRUMENT > AGENT is usually taken as natural without further discussion due to the fact that it is frequently documented in the expression of semantic roles through grammatical morphemes in Indo-European languages. However, such an evolution goes against the predictions that we can make according to the abstraction scale proposed by Heine, Claudi, and Hünnemeyer (1991:159). In their framework (see Figure 8) the expected evolution would be from an anthropocentric concept like Agent to an inanimate one (although in need of human intervention) like Instrument.

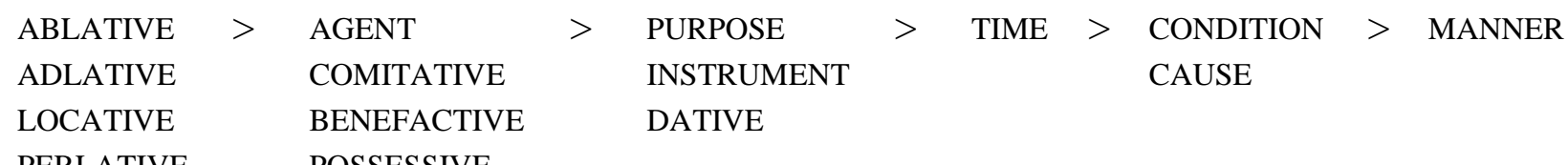

Figure 8: Abstraction scale according to Heine, Claudi and Hünnemeyer (1991:159)

The evidence that we can collect for the grammaticalization of Agents and Instruments as found in the World Lexicon of Grammaticalization (Heine and Kuteva 2002) is summarized in Figure $9 .^{18}$

\begin{tabular}{|c|c|}
\hline SOURCE & TARGET \\
\hline $\begin{array}{l}\text { ABLATIVE }> \\
\text { COMITATIVE }> \\
\text { "HAND" }> \\
\text { LOCATIVE }>\end{array}$ & AGENT \\
\hline AGENT $>$ & \\
\hline $\begin{array}{l}\text { COMITATIVE }> \\
\text { "TAKE" }>\end{array}$ & INSTRUMENT \\
\hline INSTRUMENT $>$ & $\begin{array}{c}\text { ERGATIVE } \\
\text { MANNNER }\end{array}$ \\
\hline
\end{tabular}

Figure 9: Paths of grammaticalization of Agents and Instruments (based on the data of Heine and Kuteva 2002)

As shown in Figure 9, it appears that grammatical morphemes serving for the expression of the semantic function of Agent do not evolve further, while Instruments do. In contrast to that, in word formation patterns, the evolution AGENT > INSTRUMENT is quite frequent, as we have already seen.

We would thus have in this case a different behavior in the diachronic evolution of Agent and Instrument markers as grammatical morphemes from word formation patterns. Curiously

\footnotetext{
${ }^{17}$ However, as Haspelmath (2003:239) remarks, the problem of the mental reality of the structures discovered through this methodology is very problematic.

${ }^{18}$ For the concepts of "source" and "target" of grammaticalization and how they can be framed in the general theory on grammaticalization see Heine and Kuteva (2002:6).
} 
enough, it is the semantic evolution found in word formation patterns that fits the expected pattern of evolution according to general tendencies as expressed in the abstraction scale seen above (Figure 8). This case study shows at least that we cannot take for granted that the same lines of diachronic evolution will be found in word formation patterns as in grammatical morphemes.

\section{Final Remarks}

I have tried to show in this paper how the semantic map methodology can be applied to the analysis of multifunctionality in word formation patterns, both synchronically and diachronically. A systematic program of research of the word formation patterns found in the languages of the world from this perspective can add new insights into the structure of certain conceptual domains.

Semantic maps based on word formation patterns also allow for interesting comparisons to maps drawn on the basis of grammatical morphemes. The fact that they are based on different data but semantically overlap to a certain extent can help to throw some light on the general validity of the results of this methodology. However, as Cysouw (2008) remarks, our knowledge of human language structure is still very limited, and more research is needed before we can begin to think that we are standing on solid ground in these matters.

\section{References}

Amador Rodríguez, Luis and Juan Manuel Pérez Vigaray. 2005. Los derivados españoles en -ero/a. Algunos problemas específicos de la descripción sintáctico-semántica, ed. by Juan Cuartero Otal and Gerd Wotjak, 135-144. Berlin: Franck \& Timme.

Ambros, Arne A. 1969. Zur Bedeutungsgeschichte der arabischen Nominalform fa"āl(at). Wiener Zeitschrift für die Kunde des Morgenlandes 62.87-104.

Andrews, Edna. 1996: The semantics of suffixation: Agentive substantival suffixes in contemporary Standard Russian. Munich: Lincom.

Beard, Robert. 1990. The nature and origins of derivational polysemy. Lingua 81.101-140.

Bolozky, Shmuel. 1999. Measuring productivity in word formation: The case of Israeli Hebrew. Leiden: Brill.

Chantraine, Pierre. 1933. La formation des noms en grec ancien. Paris: Champion.

Comrie, Bernard and Sandra A. Thompson. 1985. Lexical nominalization. Language typology and syntactic description, ed. by Timothy Shopen, vol. 3, 349-398. Cambridge: Cambridge University Press.

Crespo, Emilio. 1997. Sintaxis de los elementos de relación en griego clásico. Actas del IX Congreso Español de Estudios Clásicos, vol. 2, 3-42. Madrid: Ediciones Clásicas.

Croft, William. 2003. Typology and universals, 2nd edition. Cambridge: Cambridge University Press.

Croft, William, Hava B.-Z. Shyldkrot and Suzanne Kemmer. 1987. Diachronic semantic processes in the middle voice. Papers from the 7th International Conference on Historical Linguistics, ed. by Anna Giacalone Ramat, Onofrio Carruba and Giuliano Bernini, 179-192. Amsterdam: Benjamins.

Cysouw, Michael. 2008. Building semantic maps: the case of person marking. New challenges in typology, ed. by Bernhard Wälchli and Matti Miestamo, 225-248. Berlin: Mouton de Gruyter.

De Bernardo-Stempel, Patrizia. 1999. Nominale Wortbildung des älteren Irischen. Tübingen: Niemeyer. 
Dressler, Wolfgang U. 1986. Explanation in natural morphology: Illustrated with comparative and agent-noun formation. Linguistics 24.519-548.

Evans, Nicholas and David Wilkins. 2000. In the mind's ear: the semantic extension of perception verbs in Australian languages. Language 76.546-592.

Fradin, Bernard. 2005. On a semantically grounded difference between derivation and compounding. Morphology and its demarcations: Selected papers from the 11th morphology meeting, ed. by Wolfgang U. Dressler, Dieter Kastovsky, Oskar E. Pfeiffer and Franz Rainer, 161-182. Amsterdam: Benjamins.

Geeraerts, Dirk. 1997. Diachronic prototype semantics. Oxford: Clarendon.

Haspelmath, Martin. 1999. External possession in a European areal perspective. External possession, ed. by Doris Payne and Immanuel Barshi, 109-135. Amsterdam: Benjamins.

-----. 2003. The geometry of grammatical meanings: Semantic maps and cross-linguistic comparison. The new psychology of language, ed. by Michael Tomasello, vol. 2, 211-242. Mahwah, NJ: Erlbaum.

Heine, Bernd, Ulrike Claudi and Friederike Hünnemeyer. 1991. Grammaticalization: A conceptual framework. Chicago: Chicago University Press.

Heine, Bernd and Tania Kuteva. 2002. World lexicon of grammaticalization. Cambridge: Cambridge University Presss.

Kastovsky, Dieter. 1971. The Old English suffix -er(e). Anglia 89.285-325.

Kornfilt, Jaklin. 1997. Turkish. London: Routledge.

Kouwenberg, N.J.C. 1997. Gemination in the Akkadian verb. Assen: Van Gorcum.

Leumann, Manu. 1977. Lateinische Laut- und Formenlehre. Munich: C.H. Beck.

Luraghi, Silvia. 2003. On the meaning of prepositions and cases. Amsterdam: Benjamins.

Newman, Leonard, Philip Hubbard and Peter R. Prifti. 1982. Standard Albanian: A reference grammar. Stanford: Stanford University Press.

Olsen, Birgit Anette. 1988. The Proto-Indo-European instrument noun suffix *-tlom and its variants. Copenhagen: Det Kongelige Danske Videnskabernes Selskab.

Panagl, Oswald. 1977. Zum Verhältnis von Agens und Instrument in Wortbildung, Syntax und Pragmatik. Wiener linguistische Gazette 16.3-17.

Rainer, Franz. 2005. Typology, diachrony, and universals of semantic change in word-formation: A Romanist's look at the polysemy of agent nouns. Morphology and linguistic typology: Proceedings of the Fourth Mediterranean Morphology Meeting (MMM4), Catania, 21-23 September 2003, ed. by Geert Booij et al., 21-34. Università degli Studi di Bologna. Available online at http://mmm.lingue.unibo.it/proc-mmm4.php.

Rosemberg, Maria. 2007. Agent nouns, productivity and diachrony: An analysis of [VN/A]N/A compounds and -eur derivations in French. Proceedings of the Fifth Mediterranean Morphology Meeting (MMM5), Fréjus 15-18 September 2005, ed. by. Geert Booij et al., 359-377. Università degli Studi di Bologna. Available online at http://mmm.lingue.unibo.it/proc-mmm5.php.

Tichy, Eva. 1995. Die Nomina agentis auf -tar-im Vedischen. Heidelberg: Winter.

Wackernagel, Jacob and Albert Debrunner. 1957. Altindische Grammatik, vol. 2: Einleitung zur Wortlehre: Nominalkomposition. Göttingen: Vandenhoeck \& Ruprecht. 
Author's contact information:

Eugenio R. Luján

Depto. de Filología Griega y Lingüística Indoeuropea

Universidad Complutense de Madrid

Facultad de Filología. Edificio A

Ciudad Universitaria

28040 Madrid

Spain

erlujan@filol.ucm.es 